\title{
THE SUGARS AND ALBUMINOIDS OF OAT STRAW.
}

\author{
By S. H. COLLINS and B. THOMAS.
}

Agricultural Department, Armstrong College, Newcastle-on-Tme.

THE newer knowledge of nutrition shows that cereals and seed products are deficient in calcium, sodium, chlorine, and unknown substances, called fat-soluble $A$ and water-soluble $B$ sometimes referred to as "vitamines" or "accessory food factors."

McCollum(1) in America, has gone the length of proving by actual experiment that cows and their calves can be raised to perfection on nothing but the complete maize plant, although maize grain is well known as a very incomplete food. In spite of his demonstration, and in spite of the obvious fact that nothing could be more like grass than an entire cereal plant and therefore suited to herbivora, very few practical or theoretical agriculturists recognise that straw is the most likely thing in the world to correct for the deficiencies of grain feeding. The difficulty is to get straw that is eatable. The practical farmer, when he happens to get a good sample, accepts it as a gift of fate and is content to turn it into profit for himself as soon as he can. The object of the enquiry, or rather the series of enquiries of which this forms a part, is to adopt the more scientific mode of procedure and endeavour to find out what differences of feeding value naturally occur in oat straw, and which of the conditions needed for high feeding value could be repeated at will, and what light such investigation threw on the old question of why farmers in some districts can fatten cattle on swedes and straw whilst in other districts it is found impossible. Oat straw is plentiful in this country and is probably well supplied with the so-called food accessories, that is the things that the grains lack; the problem at issue is how to get more of the eatable kind and less of the uneatable kind. Provided that the straw is eaten in fair quantity, the possible diminution of growth power, by partial destruction of vitamines due to keeping straw in the stack, is of no practical importance because of the large amount of the straw.

The first subject attacked was the sugar content, but it was found during the progress of the investigations that the albuminoids were 
equally promising as a subject of enquiry. It is worthy of note that whereas the chief digestible carbohydrate of oat grain is starch, which is condensed dextrose, the sugar of the straw is chiefly laevulose. In other words, straw supplies the feeding deficiency of oat grain, if cane sugar, which is a condensed form of both sugars together, is considered the complete food sugar.

Samples of oat straw from many parts of Great Britain have been examined for their chief constituents and as far as possible the conditions under which the straw was grown have been recorded. From the results obtained, averages of groups of results are given in the following notes. The general method of analysis follows common practice for oil, albuminoids, fibre and ash. The estimation of laevulose has been described by one of us(2), the estimation of the other sugars being by Fehling's volumetric method. At times the method of Ling (3) was used for an end point but in most cases the solutions were sufficiently free from colour to render Ling's indicator superfluous. At times the oat straws were extracted with ether to remove some substances that prevented the cuprous oxide from settling (4) but in most cases these precautions proved unnecessary. Nevertheless the authors consider that both methods are very valuable at times when difficulties arise. As regards Ling's indicator the authors found that a simpler recipe worked even better. A small ball rolled up from about half a yard of flower wire was placed in a test tube with 2 c.c. hydrochloric acid and 2 c.c. water and boiled for one minute. A small spoonful (about $\frac{1}{2} \mathrm{gm}$.) of ammonium sulpho-cyanide was added and allowed a minute or two to stand and cool. This indicator kept, in its original test tube with the residue of the iron wire, very well for a week or two, since fresh iron dissolved as fast as oxidation took place. Also carbon oxysulphide is formed which acts as a reducing agent. In practice it is better to make fresh indicator daily. In early. samples pentoses were looked for, but either none or the merest traces could be found. From the polarimetric readings and other properties the unidentified sugar appears to be mostly dextrose.

The albuminoids are the usual $\mathrm{N} \times 6 \frac{1}{4}$ figures. All the early samples were also treated so as to give the ammonia volatile with steam and 10 per cent. potash and the nitrogen insoluble in various "protein precipitants." In the end it was found that the $\mathrm{N}$ precipitated by basic lead acetate and the $\mathrm{N}$ volatile as $\mathrm{NH}_{3}$ by steam and potash almost exactly added up to the total $\mathrm{N}$ and that other $\mathrm{N}$ precipitants were uncertain. Further the amount of "non-albuminoid" nitrogen as deduced from such estimations was too small in amount to have much 
practical value. Normal lead acetate gave concordant results but left a considerable fraction unaccounted for. Copper hydrate gave very discordant results. The $\left(\mathrm{N} \times 6 \frac{1}{4}\right)$ precipitated by basic lead acetate added to the $\left(\mathrm{N} \times 6 \frac{1}{4}\right)$ volatile with steam and potassium hydroxide gave a result on the average of 70 tests of .005 per cent. above the total $\left(\mathrm{N} \times 6 \frac{1}{4}\right)$. The average difference between the sum of those two parts and the whole, neglecting signs, was $\cdot 184$ per cent. Of the 70 samples thus fully analysed the average "albuminoids" was 3.26 per cent. and the average "amides" was .29 per cent. or only 8.9 per cent. of the total.

\section{Effect of Manure on the Composition of Oat Straw.}

The compilation of averages of large numbers of trials, such as these, presents many difficulties. Classification is often rather difficult and some observations must be rejected as not capable of classification. By dividing the results of the analysis of oat straw into three groups we find the following figures. Unless otherwise expressed the results have been calculated from 1919, 1920 and 1921 crops.

A. 35 samples of oat straw grown with very much organic nitrogen such as ploughed in leas, apparently rich, omitting doubtful "clover takes" but including land with heavy dressings of dung.

$\begin{array}{lllll}\text { Laevulose } . . . & \ldots & \ldots & 1.05 \% & \pm .11 \\ \text { Total sugar } & \ldots & \ldots & 2.51 & \pm \cdot 24 \\ \text { Albuminoide } & \ldots & \ldots & \mathbf{3 . 8 4} & \pm \cdot 13\end{array}$

B. 29 samples of oat straw top dressed with sulphate of ammonia.

$\begin{array}{lllll}\text { Laevulose ... } & \ldots & \ldots & 1.62 \% & \pm \cdot 21 \\ \text { Total sugar } & \ldots & \ldots & 3 \cdot 28 & \pm \cdot 24 \\ \text { Albuminoids } & \ldots & \ldots & 2.54 & \pm \cdot 12\end{array}$

C. 21 samples of oat straw grown with little if any nitrogenous manure in any form.

$\begin{array}{lllll}\text { Laevulose ... } & \ldots & \ldots & 1.65 \% & \pm \cdot 28 \\ \text { Total sugar } & \ldots & \ldots & 3.47 & \pm \cdot 45 \\ \text { Albuminoids } & \ldots & \ldots & 2.57 & \pm \cdot 16\end{array}$

The combinations of these results which give significant differences are: Much organic nitrogen gives an oat straw richer in albuminoids than that given by little or no nitrogen, to the extent of $1.27 \% \pm \cdot 22$, as judged by 56 tests. Much organic nitrogen gives an oat straw richer in albuminoids than that given by sulphate of ammonia top dressings, to the extent of $1 \cdot 30 \% \pm \cdot 21$, as judged by 64 tests. Organic nitrogen manures give oat straw richer in albuminoids than that given by all other manures, to the extent of $1 \cdot 28 \% \pm \cdot 17$, as judged by 85 tests.

Oiher probable results are: Organic nitrogen manures depress the amount of laevulose in oat straw to the average extent of $\cdot 59 \% \pm \cdot 21$. 
Sulphate of ammonia is better than organic nitrogen for sugar production but only to a small extent.

\section{EFfect of Districts.}

It was quite impossible to do more than select a few farms to represent large areas. The conclusions arrived at can by no means be supposed to refer to the whole of the district alluded to. In some cases personal knowledge permitted the farms to be well scattered, so that County Durham is fairly well represented, but the district called Scotland is merely an average of a few results from Aberdeen and Edinburgh and is therefore merely a name for places well to the north of Northumberland. Similarly Yorkshire is represented almost entirely by Garforth, only a few other places in the county being among the list of farms from which samples were obtained. The southern counties district is more widespread, as it includes Essex, Herts, Bucks, Hants, Wilts, Derby and Notts, and may fairly represent "the South" from a north countryman's point of view.

In spite of these drawbacks in the classification, a useful comparison may be made with the following results.

\section{Albuminoids in Oat Straw in Different Districts.}

Moving from North to South:

Scotland with 20 samples gives $3.23 \% \pm \cdot 10$.

Northumberland and Durham with 26 samples gives $3 \cdot 15 \% \pm \cdot 14$.

Cumberland and Westmorland with 15 samples gives $4.42 \% \pm \cdot 15$.

Yorkshire with 27 samples gives $3.09 \% \pm \cdot 08$.

Southern Counties with 34 samples gives $2 \cdot 74 \% \pm \cdot 09$.

The outstanding result is the much higher amount of albuminoids in Cumberland and Westmorland. Oats are there a very important crop as they receive much more manure than is customary in other parts. They frequently follow old leas and often receive much direct application of dung. Stock are moreover the central feature of the system of farming and much care is taken of the beasts. Owing to the damper climate it is possible that the roots of the oats go on absorbing nitrogen to a late stage and hence keep on accumulating nitrogen; but the average figures for non-albuminoid nitrogen are not especially high, so that some other explanation must be looked for. The superiority of the oat straw on the farms tested in Cumberland and Westmorland can hardly be attributed to any other cause than an increased amount of available nitrogen in the soil. 


\section{The Sugars and Albuminoids of Oat Straw}

If we put Cumberland and Westmorland aside and compare the other districts there is at once the striking result that albuminoids increase directly with latitude. The difference between the Scottish figure, and those from the southern counties is marked and is quite in accordance with the popular impression that straw can be fed in Scotland in a way in which it cannot be fed in the south of England. At Cockle Park one experiment with different seed dates showed that the total nitrogen in the crop per acre was not very different; with autumn sown oats, the large crop of grain took nearly all the nitrogen, but the spring sown oats gave only half the grain yield and left a straw very rich in albuminoids. It follows that in Scotland with its shorter growing season the grain will not be able to exhaust the straw to the same extent as it would in England and that therefore Scottish oat straw will on the average contain more albuminoids than English oat straw. The conclusion is in close accord with the results based on the statistics.

A partial answer is here given to the well-known question: why can cattle be fattened on straw and roots in Scotland and not in the south of England? It is due to the superiority of north country straw in albuminoids. Quite possibly along with the albuminoids may go those little understood food accessory substances already alluded to. Swedes and turnips are very poor in albuminoids and the superiority of northern straw in this respect may be the determining factor. At Cockle Park, in feeding trials on hay, the determining factor is often the percentage of albuminoids. North country hay is poor in albuminoids whereas north country oat straw is relatively rich, or one might say south country hay is relatively rich and south country straw relatively poor. These two facts together go a long way to explain the respective practices in feeding cattle. The variation in the albuminoids in oat straw grown in different districts may possibly be partly due to rainfall. In Scotland, Northumberland, Durham and Yorkshire the average rainfall at the places where the oats were grown was about 30 inches, but the Cumberland and Westmorland areas have an average rainfall about 45 inches and the southern counties area about 27 inches. Among other causes of high proportions of albuminoids may be placed a good supply of water. Oats that are cut green will often be cut green because the season is wet with the result that the straw contains more albuminoids. Hence the cattle relish the straw and the farmer says that the straw is "sweet" but it is rich in albuminoids and not particularly rich in sugar. 


\section{The District in which Oats are grown and the amount of Sugar in the Straw.}

Seasonal influences play such a great part in sugar production and content that 1920 and 1921 do not give the same relationships.

In 1920, Cumberland and Westmorland headed the list and Northumberland and Durham were only a little behind the four northern counties, giving total sugar $4.48 \% \pm \cdot 29$ with the rest of Great Britain at $1.69 \% \pm \cdot 12$. In 1921 however the southern counties gave $4 \cdot 76 \% \pm \cdot 34$ and the four northern counties $1.80 \% \pm \cdot 15$ the average of all except the southern counties being $1.44 \% \pm \cdot 10$. From these results it is clear that the southern counties made good use of the dry season of 1921.

As in former years samples of oat straw which contain much total sugar also contain much laevulose, so that the laevulose varies from 50 to 70 per cent. of the total sugar, but when the total sugar is low in amount laevulose is often absent. On the average of all results, poor and rich, the laevulose is a little under 50 per cent. of the total but even then it is the commonest sugar, since the remainder is divided between cane sugar and dextrose and perhaps traces of other sugars.

\section{General Conclusions.}

Fine weather during harvest appears essential for obtaining high percentages of sugar. Sugar gradually disappears from straw after harvest. When straw is very dry the loss is small, but if damp, sugar is readily lost. Under average practical conditions high sugar content is not common but, under careful management, oat straw six months old has given very high figures for sugar. Roughly it might be said that the more nitrogen a soil contains the more albuminoids there will be in the straw, but much will depend on the amount of grain produced.

The general impression obtained during the course of these investigations is that the reason why feeding oat straw and swedes is so successful in one district and not in another may be summed up in the phrase "good husbandry." When a farmer understands and is keen on cattle he obtains more dung, which gives him better quality straw and roots. Feeding these again skilfully to more beasts gives him still more and still richer dung until in the limit of practice he is able to feed beasts almost entirely on straw and roots because both are rich in albuminoids. The lowest figure for albuminoids is 1.12 per cent. and the highest 8.05 per cent.; a variation more than enough to explain any 
difference in feeding value. Poor samples of hay are often below 8 per cent. albuminoids. The highest total sugar is 9.74 per cent. and the lowest 0.33 per cent. Old leas ploughed out and plenty of muck give high albuminoids; fine harvest weather gives sugars. It is good management that secures the benefits of these improvements in composition.

\section{The Value of Research Grants.}

Twenty-two years ago one of us started to answer the question "why can cattle be fattened on roots and straw in Scotland and not in England?" Limitation of time restricted the enquiry to lines which looked promising, with little direct result although the experience has in the end proved very valuable. Thanks to a Special Research Grant from the Ministry of Agriculture, a very moderate extra expenditure has enabled the enquiry to be prosecuted in a complete manner. Out of this came the idea that perhaps it was the albuminoids in the straw that was the foundation on which an answer could be given; further work has shown that that is undoubtedly the case, as far as the main part of the answer is concerned. Nevertheless the sugar is important in both swedes and straw and contributes a great deal to the feeding value, but probably it is the albuminoids in the straw that make the chief difference between the practice of north and south.

\section{BLBLIOGRAPHY.}

(1) McCoulum. The Newer Knowledge of Nutrition (MacMillan), p. 100.

(2) Collins. The Estimation of Laevulose (Fructose) in Straw. J.S.C.I. 1922, p. $56 . \mathrm{T}$.

(3) LrNa and Jones. Volumetric Estimation of Reducing Sugars. Analyst, 1908, p. 160.

(4) Coulins and Spmurr. Sugar in Oat Straw and Cattle Food. J.S.C.I. 1920, p. 66. T. 